\title{
Conceptualisation of Employee Voice: Definitions, Typologies and Measurement
}

\author{
Larysa Botha \\ Graduate School of Business Leadership, University of South Africa \\ PO Box 392, UNISA 0003, South Africa \\ E-mail: Larysa@vodamail.co.za \\ Renier Steyn \\ Graduate School of Business Leadership, University of South Africa \\ PO Box 392, UNISA 0003, South Africa \\ E-mail: steynr@unisa.ac.za
}

Received: May 52020 Accepted: July 27, 2020 Online published: August 6, 2020

doi:10.5296/ijhrs.v10i3.17495 URL: https://doi.org/10.5296/ijhrs.v10i3.17495

\begin{abstract}
Background: Voice, as an important employee behaviour, channels ideas, concerns, and suggestions upward in the organisation and is often the only way for managers to become aware of issues and problems that, potentially, may be detrimental to the organisation's performance. Aim: The aim of this article is to present a review on the conceptualisation of voice, with the focus on the different ways in which the concept is defined, categorised and measured. This is required as a comprehensive and contemporary operationalisation of voice and will ensure that future research is linked to the dominant body of knowledge. Setting: Literature presents employee voice behaviour in divergent ways, which applies to the definition, typologies and measurement of voice. This divergence poses a challenge for researchers and practitioners alike. Method: A comprehensive literature review was conducted to obtain a large spectrum of definitions, categorisations and assessments of voice. These were examined for breadth of adoption, consensus in terms of elements and, in the case of assessment, the acceptability of psychometric properties of measuring instruments. Results: After reviewing a substantial number of the articles published in peer-reviewed journals between the years 1970 and 2019, the three most popular definitions of voice are presented, the three most common conceptualisations on the forms/types of voice identified, and three
\end{abstract}


most-used measuring scales with acceptable validity and reliability acknowledged. The definition, typologies, and measuring instrument proposed by Maynes and Podsakoff (2014) seems to be the standard in voice research. Their theorising on all three aspects is well accepted and forms the basis for many recent studies on voice. Conclusion: Building on previous research, and considering recent publications, the comprehensive conceptualisation of voice is best described by the seminal work of Maynes and Podsakoff (2014), which integrates the extant knowledge on the topic and how it is operationalised. Managerial implications: Researchers and practitioners are now aware of most adopted and authoritative conceptualisations of employee voice behaviour, which should provide them with greater confidence to engage in discussions on the topic as well as in facilitating research in the future.

Keywords: employee voice, definition, typology, psychometric assessment

\section{Introduction}

As a behavioural concept, voice has attracted attention from researchers due to its pervasive characteristics and effects on organisations (Van Dyne, Ang, \& Botero, 2003). It is proposed that there are two streams of research that conceptualise voice: one that studies voice as a speaking up behaviour of employees proactively offering inputs and ideas for improvements (organisational development (OD) perspective), and another that describes voice in the sense of the presence of internal organisational mechanisms, such as processes and procedures to enhance employees' participation in decision making (Human Resource/Employment Relations (HRM/ER) perspective) (Mowbray, Wilkinson, \& Tse, 2015; Van Dyne et al., 2003). The OD perspective focuses on informal processes while the HRM/ER perspective focuses on institutionalised and formal processes. These divergent approaches attracted criticism due to the lack of conceptual consistency between them (Maynes \& Podsakoff, 2014; Morrison, 2011). While advocating for the OD perspective in studying voice for its discretionary properties, Morrison (2011) rejects the HRM/ER approach for its reference to a varied range of formal mechanisms through which employees can provide inputs (e.g. grievance procedures, suggestion boxes, quality circles and work councils). In agreement with Morrison (2011), and while recognising the merits of both perspectives in addressing managerial implications, this article deliberately conceptualises voice from the OD perspective, focusing on informal rather than institutionalised voice. This focus is underpinned by the conviction that discretionary behaviour is essential to innovation (Bos-Nehles, Renkema, \& Janssen, 2017; Sanz-Valle \& Jiménez-Jiménez, 2018; Veenendaal, 2015), an element fundamental to organisational survival (Agarwal, 2014).

The article will present the concept of voice, starting with the development of definitions of voice and leading on to a description of voice typologies. Thereafter, it will present relevant instruments for measuring voice. In each case, the contributions of three of the most prominent groups of authors concerning each aspect will be discussed.

\section{Definition of Voice}

The concept of voice originated in the early seventies when Hirschman (1970) developed 
Exit-Voice-Loyalty theory. This theory proposes that customers who are dissatisfied with a company's offering - be it a service or product - have two choices: either to exit (to withdraw from the relationship) or to voice (attempt, by remaining loyal, to effect changes in that company's processes and practices). Hirschman defined voice as "any attempt at all to change, rather than to escape from, an objectionable state of affairs, whether through individual or collective petition to the management directly in charge, through appeal to a higher authority with the intention of forcing a change in management, or through various types of actions or protests, including those that are meant to mobilize public opinion" (1970, p. 30).

Following on Hirschman's work on customer dissatisfaction, the concept of voice evolved significantly. It was extended to workers of organisations and came to be perceived not only as a means of communication with management (Freeman \& Medoff, 1984, p. 8), but also as an opportunity to provide "meaningful" inputs into management's decisions (Budd, 2004, p. 23).

Following an extensive literature review, it became clear that, after publication of the seminal paper on voice by Van Dyne and LePine (1998), three groups of authors dominated the way in which development of voice took place post-1998. These were Morrison (2011), Liang, Farh and Farh (2012) and Meynes and Podsakoff (2014). Their contributions are discussed below.

Morrison (2011) provides definitions of voice by various authors and these are summarised in Table 1, below.

The table leads with the definition presented as part of the seminal paper by Van Dyne and LePine (1998).

Table 1. Definitions of voice

\begin{tabular}{ll}
\hline \multicolumn{1}{c}{ Author } & \multicolumn{1}{c}{ Definition } \\
\hline Van Dyne and LePine (1998) & $\begin{array}{l}\text { Promotive behaviour that emphasises expression of } \\
\text { constructive challenge intended to improve rather than merely } \\
\text { criticise. Making innovative suggestions for change and } \\
\text { recommending modifications to standard procedures even } \\
\text { when others disagree (p.109) }\end{array}$ \\
LePine and Van Dyne (1998) & $\begin{array}{l}\text { Non-required behaviour that emphasises expression of } \\
\text { constructive challenge with the intent to improve rather than } \\
\text { merely criticise (p.854) }\end{array}$ \\
Van Dyne, Ang and Botero & $\begin{array}{l}\text { Intentionally expressing rather than withholding relevant } \\
\text { ideas, information, and opinions about possible work-related } \\
\text { improvements (p.1360) }\end{array}$ \\
Premeaux and Bedeian & $\begin{array}{l}\text { Openly stating one's views or opinions about workplace } \\
\text { matters, including the actions or ideas of others, suggested or } \\
\text { (2003) }\end{array}$ \\
needed changes, and alternative approaches or different lines \\
of reasoning for addressing job-related issues (p.1538) \\
The discretionary provision of information intended to \\
improve organisational functioning to someone inside the
\end{tabular}


organisation with the perceived authority to act, even though such information may challenge and upset the status quo of the organisation and its powerholders (p.869)

Verbal behaviour that is improvement-orientated and directed to a specific target who holds power inside the organisation in question (p.870)

Tangirala and Ramanujam (2008b)

Employees' expression of challenging but constructive options, concerns, or ideas about work-related issues (p.1189)

Source: Morrison (2011, p. 376)

Morrison (2011) points out that there are three common features shared by these definitions. Firstly, the idea of voice is understood as a verbal expression of the message from the sender to the recipient. Secondly, it is understood as a discretionary behaviour; the act of voice is not an obligation nor an expected behaviour (Van Dyne, Cummings, \& Parks, 1995). Finally, the intent of voice is regarded as constructive and positive in nature (Morrison, 2011).

Based on definitions appearing in the literature prior to 2011, Morrison offers an integrated, conceptualised description of voice as a "discretionary communication of ideas, suggestions, concerns, or opinions about work-related issues with the intent to improve organisational or unit functioning" (2011, p. 375). Morrison further agrees with the classification of voice by Van Dyne, Cummings and Parks (1995) as a form of "challenging/promotive" extra-role behaviour.

After Morrison, the next significant contribution in defining voice is made by Liang, Farh and Farh (2012). While viewing the concept as a mechanism of speaking up with suggestions as well as concerns, as proposed by Van Dyne, Ang and Botero (2003), Liang et al. (2012) distinguish between two opposite types of voice - promotive and prohibitive - representing a departure from the unitary approach towards multidimensional conceptualisation of voice. Liang et al.'s (2012) definition of promotive voice resonates with the original conceptualisation of voice by Van Dyne and LePine (1998) and Morrison (2011), referring to it as "employees' expression of new ideas or suggestions for improving the overall functioning of their work unit or organization" (2012, p. 74). By contrast, Liang et al. (2012, p. 75) define prohibitive voice as "employees' expressions of concern about work practices, incidents, or employee behaviour that are harmful to their organization". Introducing a conceptual boundary between two forms of voice, where promotive voice focuses on intents of realising ideas and opportunities, and prohibitive voice focuses on intents of stopping or preventing problematic initiatives from taking place, Liang and colleagues call for future explorations of these two content domains of voice.

While the definitions put forward by Morrison and Liang and his team make progress towards refining the meaning of voice, recent researchers have been in pursuit of updating the definition of the concept even further. For example, Rees, Alfes and Gatenby (2013, p. 2783) see voice as "referring specifically to employees' actual behaviour in 'speaking up' with constructive ideas that aim to improve or change the status quo". Rees et al. (2013) seem to agree with the earlier definition of Detert and Burris (2007, p. 869) who refer to voice as 
"discretionary provision of information with intention to improve organisational functioning", and who then add "even though such information may challenge the status quo of the organization and its power holders, is critical to organisational well-being yet insufficiently provided by employees, who see the risks of speaking up as outweighing the benefits". The link between challenging the status quo along with managerial actors within the organisation and the risks attached to speaking up is a valuable augmentation of voice concept which prompted Meynes and Podsakoff (2014) to further expand their view on voice.

In their prominent research paper titled "Speaking more broadly: An examination of the nature, antecedents, and consequences of an expanded set of employee voice behaviours", Meynes and Podsakoff (2014) evaluated and integrated previous conceptions of voice behaviour that had come to light during the preceding 15 years. Each of these conceptions highlights specific characteristics of voice and, combined, include the following set of voice attributes: a) voice behaviour being exhibited by individual employees, b) employees not remaining silent, anonymous or neutral, c) these behaviours conspicuously staking out an employee's position relative to the status quo, and d) because others in the organization may disagree with the voicing employee's position, the possibility of voicing damaging interpersonal relationships at work (Maynes \& Podsakoff, 2014, p. 88). Based on these several core attributes of voice, the authors proposed their definition of voice as an "individual's voluntary and open communication directed toward individuals within the organization that is focused on influencing the context of work environment" $(2014$, p. 88). Furthermore, the authors summarise that the expression of behaviour, if it is to be considered voice, needs to match the following commonly defined criteria: a) it must be communicated openly, b) it needs to be organisationally relevant, c) it must focus on influencing the work environment, and d) it needs to be directed to someone inside the organisation $(2014$, p. 88$)$.

Although it seems that, in general, a consensus exists amongst researchers, there are examples of evident disparities between recent definitions of voice. Whilst the majority of definitions specify that employees' communication (as voice) is directed toward recipients within the organisation (Barry \& Wilkinson, 2016; Detert \& Burris, 2007; Maynes \& Podsakoff, 2014), there are also definitions that include both, internal and external to the organisation, targets to whom the ideas, opinions and suggestions are directed (Bashshur \& Oc, 2015). This divergence supports the recent call for further clarity on the nature, characteristics and conceptualisation of employee voice (Mowbray et al., 2015).

\subsection{Discussion}

Although the definitions of voice presented here share a number of common features and characteristics, the definition by Maynes and Podsakoff (2014) reflects the most prominent attributes of the concept as expressed by various authors in their works during recent decades and also represents the expanded and integrated conceptualisation of voice behaviour. For this reason, their definition of voice as an "individual's voluntary and open communication directed toward individuals within the organization that is focused on influencing the context of work environment" (Maynes \& Podsakoff, 2014, p. 88), is proposed as the anchor for the conceptual grounding of research on voice. 
Next, various types of voice will be identified and reviewed.

\section{Typologies of Voice}

A number of scholars differentiated between various types of voice, most commonly characterised as constructive, considerate, aggressive, destructive and prohibitive forms of voice (Gorden, 1988; Liang et al., 2012; Morrison, 2011; Van Dyne \& LePine, 1998).

In recent years, more typologies have been added and, among these, the works of three groups of authors have sparked the most attention. Firstly, Van Dyne et al. (2003) came up with a voice typology that complements the typology of silence, which is defined as a collective phenomenon where employees withhold their opinions and concerns about potential organisational problems (Morrison \& Milliken, 2000). Then Liang et al. (2012), applying a greater degree of nuance, differentiated between two types of voice based on the promotive or prohibitive nature of the message conveyed to the recipients of the message. Lastly, Maynes and Podsakoff (2014) constructed a framework of employee voice behaviour along two sets of dimensions: the first set contrasts behaviours that preserve the status quo and behaviours that challenge the status quo, while the second set contrasts promotive voice behaviours and prohibitive voice behaviours.

This section will examine three main streams of research related to various typologies of voice. The works, organised in chronological order and starting with Van Dyne et al. (2003), followed by Liang et al. (2012), and then by Maynes and Podsakoff (2014), will be emphasised. The typology by Maynes and Podsakoff (2014) is selected for this research and will be examined in more detail than others.

Van Dyne et al. (2003, p. 1361) proposed that "purposeful" forms of both silence and voice exist. In their assertion that silence is not the opposite of voice, the authors propose that the main differentiating factor between the two is the "actor's motivation to withhold versus expressing ideas, information, and opinions about work-related improvements".

Three types of silence and three corresponding types of voice are organised within a $2 \times 3$ framework, as illustrated in Table 2, below:

Table 2. Examples of specific types of silence and specific types of voice

\begin{tabular}{llll}
\hline $\begin{array}{c}\text { Behaviour } \\
\text { drive } \\
\text { (motive) }\end{array}$ & Behavioural type & \multicolumn{1}{c}{ Behavioural options } \\
\hline $\begin{array}{l}\text { Feeling } \\
\text { unable to } \\
\text { make a }\end{array}$ & $\begin{array}{l}\text { Disengaged } \\
\text { behaviour }\end{array}$ & Acquiescent silence & Acquiescent voice \\
difference & Examples: & Examples: \\
(Based on & Withholding ideas based & $\begin{array}{l}\text { Expressing supportive ideas } \\
\text { based on resignation }\end{array}$ \\
resignation) & on resignation & $\begin{array}{l}\text { Agreeing with the group due } \\
\text { Keeping opinions to self } \\
\text { due to low self-confidence } \\
\text { to make a difference }\end{array}$ & $\begin{array}{l}\text { to low self-efficacy to make } \\
\text { a difference }\end{array}$ \\
\hline
\end{tabular}


Feeling afraid and personally at risk (Based on fear)
Self-protective

behaviour
Defensive silence

Examples:

Withholding information on problems based on fear

Omitting facts to protect the self 2020, Vol. 10, No. 3

Defensive voice

Examples:

Expressing ideas that shift attention elsewhere based on fear

Proposing ideas that focus on others to protect the self

\begin{tabular}{l}
\hline Feeling \\
cooperative \\
and altruistic \\
(Based on \\
cooperation)
\end{tabular}

$\begin{array}{ll}\begin{array}{ll}\text { Other-orientated } \\ \text { behaviour }\end{array} & \text { Pro-social silence } \\ & \text { Examples: } \\ & \text { Withholding confidential } \\ & \begin{array}{l}\text { information based on } \\ \text { cooperation }\end{array}\end{array}$

Protecting proprietary knowledge to benefit the organization

\section{Examples:}

Expressing solutions to problems based on cooperation

Suggesting constructive ideas for change to benefit the organisation

Source: Adapted from Van Dyne et al. (2003, p. 1363)

Employee silence and voice are organised in the framework along two dimensions: type of behaviour and type of motivation. Three specific types of silence and voice (acquiescent, defensive and pro-social) are described according to three specific employee motives (disengaged, self-protective and other-orientated).

Contrasted as two important employee behaviours, both silence and voice are divided into three corresponding types: pro-social silence and voice, defensive silence and voice, and acquiescent silence and voice. Discussion of these follows.

- Pro-social voice.

Similar to pro-social silence, pro-social voice is proactive, intentional, requires effort, and is recognised as a form of OCB (Robinson, 1996; Robinson \& Morrison, 1995; Van Dyne \& LePine, 1998). Pro-social voice is defined as a behaviour of "expressing work-related ideas, information, or opinions based on cooperative motives". Pro-social voice is not intended to focus on self, rather, it is intended to benefit others, such as the organisation (Van Dyne et al., 2003, p. 1371).

- Defensive and acquiescent voice.

Defensive and acquiescent voice is derived from the concept by Morrison and Milliken (2000) that these two types of silence exist: one being silence based on fear (defensive silence) and the other being silence based on inability to make a difference (acquiescent silence), Van Dyne et al. (2003) propose two parallel types of voice, defensive voice and acquiescent voice.

Defensive voice is characterised by "expressing work-related ideas, information or opinions based on fear - with the goal of protecting self". Acquiescent voice, then, is characterised by disengagement and "expressing work-related ideas, information, or opinions - based on feelings of resignation" (Van Dyne et al., 2003, p. 1372) and stems from feelings of being 
unable to make a difference.

The authors argue that unlike the unitary concept of voice, this typology of voice is more precise and will allow for a further refining of empirical studies (Van Dyne et al., 2003, p. 1370).

Liang et al. (2012, p. 72), while describing voice as an intentional, "planned behaviour" which is discretionary and largely beneficial for organisational functioning, distinguish between two types of employee voice: promotive and prohibitive.

- Promotive voice, defined earlier as “employees' expression of new ideas or suggestions for improving the overall functioning of their work unit or organization" (2012, p. 74), and

- Prohibitive voice defined as “employees' expressions of concern about work practices, incidents, or employee behaviour that are harmful to their organization" (2012, p. 75).

Liang et al. propose that promotive and prohibitive voice types share some common characteristics, for example, both are considered "extra-role" behaviours, constructive in nature and motivated by the individual's desire to help. They differ in behavioural content (expressing ideas vs concerns), their function (pointing towards organisational improvements vs pointing out factors that are harmful to the organisation) and implications for others (positive interpretation of suggested improvements vs negative emotions of those responsible invoked by exposing harmful factors). Table 3 provides a comparison between the two types of voice. 


\section{Macrothink}

International Journal of Human Resource Studies

Table 3. Distinctions and commonalities between promotive and prohibitive voice types

\begin{tabular}{ll}
\hline Characteristics & Promotive Voice \\
\hline $\begin{array}{l}\text { Distinctions } \\
\text { Behavioral content }\end{array}$ & $\begin{array}{l}\text { Expresses new ideas or } \\
\text { solutions for how to impro } \\
\text { the status quo. }\end{array}$ \\
- $\begin{array}{l}\text { Future-oriented; points to } \\
\text { possibilities of how to do } \\
\text { things better in the future. }\end{array}$
\end{tabular}

Function

Implications for others
- Points out ways that the organization can be better.
Prohibitive Voice

- Expresses concern about existing or impending factors (i.e., incidents, practices, or behaviors) that are harmful to the organization.

- Past or future-oriented; points out harmful factors that have negatively affected the status quo or could have a harmful effect in the future.

- Points out factors that are harmful to the organization.

- Calls attention to harmful factors and consequently implicates the failure of those responsible. short run, but the improvements can potentially eventually benefit the entire community.

- The good intention behind suggested improvements is easily recognized and interpreted as positive.

- The good intention behind pointing out harmful factors may not be easily recognized or interpreted as positive because of the potential negative emotion and defensiveness invoked in the process.
Commonalities
- Is not specified in formal job descriptions (save for particular jobs such as auditing) and this is "extra-role".

- Is helpful to the functioning of an employee's work unit or organization and thus is "constructive".

- Is motivated by a desire to help the work unit or organization and thus reflects the employee's sense of responsibility and constructive attitude toward the organization.

Source: Liang et al. (2012, p. 75)

Although Liang et al.'s (2012) typology has gained popularity amongst researchers in recent 
years (e.g. (Chamberlin, Newton, \& LePine, 2017; Jada \& Mukhopadhyay, 2018; Wang, Zheng, \& Zhu, 2018)), it has also attracted criticism predominantly for viewing prohibitive voice as a constructive behaviour intended to stop or prevent practices perceived as damaging to the organisation (Maynes \& Podsakoff, 2014). One of the arguments for such criticism is the fact that employees do not necessarily voice their opinions or suggestions in a constructive manner (Maynes \& Podsakoff, 2014). The typology that will be discussed next reconciles this issue and suggests that prohibitive voice behaviour can be either constructively or destructively orientated.

Maynes and Podsakoff (2014, p. 87), in response to the criticism of earlier research on voice behaviour for lack of conceptual clarity on defining voice, poor measurement scales and inconsistent empirical results, introduced a new, "more expansive view" of voice behaviour. There are two distinct outcomes of their work. Firstly, while synthesising the previous research, the authors developed a new voice behaviour framework with four types of voice and provided definitions and characteristics for each of these. Secondly, the authors developed and validated measures for each type of voice behaviour.

Built on earlier research in terms of dimensions between which voice behaviour may vary (Gorden, 1988; Hirschman, 1970; Liang et al., 2012; Van Dyne et al., 2003; Van Dyne \& LePine, 1998), Maynes and Podsakoff's framework similarly arranged voice behaviours along the two continuums. The opposite dimensions of voice behaviour on the first continuum are behaviours that preserve the status quo and behaviours that challenge the status quo. The opposite dimensions of voice behaviour on the second continuum are promotive voice behaviours and prohibitive voice behaviours. By organising these four dimensions within a 2 x 2 matrix, Maynes and Podsakoff propose four types of voice behaviour corresponding with four domain quadrants.

Table 4 below, illustrates Maynes and Podsakoff's (2014) voice organising framework, where each type of voice behaviour is defined, characteristics of representative behaviour are described, and related constructs are provided.

Table 4. Organising framework for employee voice behaviour

\section{Supportive Voice \\ (Preservation + Promotive)}

Definition:

Supportive voice is the voluntary expression of support for worthwhile work-related policies, programmes, objectives, procedures, etc., or speaking out in defence of these same things when they are being unfairly criticised.

\section{Constructive Voice}

(Challenge + Promotive)

\section{Definition:}

Constructive vice is a voluntary expression of ideas, information or opinions focused on effecting organisationally functional change to the work context. 
Representative behaviours:

Expressing support for organisational procedures or objectives

Verbally defending organisational policies that other employees are criticising

Related constructs:

Acquiescent voice (Van Dyne et al, 2003)

Active/constructive voice (Gorden, 1988)

Passive/constructive voice (Gorden, 1988)

Loyalty (Graham, 1991)

\section{Representative behaviours:}

Suggesting improvements to standard operating procedures

Proposing ideas for new or more effective work methods

Related constructs:

OCB voice (Van Dyne and LePine, 1998)

Pro-social voice (Van Dyne et al, 2003)

Promotive voice (Liang et al, 2012)

Prohibitive voice (Liang et al, 2012)

\section{Defensive voice \\ (Preservation + Promotive)}

\section{Definition:}

Defensive voice is a voluntary expression of opposition to changing an organisation's policies, procedures, programmes, practices, etc., even when the proposed changes have merit or making changes is necessary.

\section{$\underline{\text { Representative behaviours: }}$}

Vocally opposing changes to work practice, even though the changes are necessary

Speaking out against changing work policies, even when the changes have merit

\section{Related constructs:}

Defensive voice (Van Dyne et al, 2003)

Resistance to change (Oreg, 2003)

\section{Destructive voice}

\section{(Challenge + Prohibitive)}

\section{Definition:}

Destructive voice is the voluntary expression of hurtful, critical, or debasing opinions regarding work policies, practices, procedures, etc.

\section{$\underline{\text { Representative behaviours: }}$}

Bad-mouthing the organisation's policies or objectives

Making overly critical comments about how things are done in the organisation

$\underline{\text { Related constructs: }}$

Active/destructive voice (Gorden, 1988)

Poor sportsmanship (Organ, 1988)

Adapted from Maynes and Podsakoff (2014, p. 91)

As shown in Table 4, the four distinct types of voice are defined and described in the following ways:

- Supportive voice - "is the voluntary expression of support for worthwhile work-related policies, programs, objectives, procedures, etc., or speaking out in defence of these same things when they are being unfairly criticized". Supportive voice is closely related to acquiescent voice construct of Van Dyne et al. (2003). 


\section{Macrothink}

International Journal of Human Resource Studies

ISSN 2162-3058

2020, Vol. 10, No. 3

- Constructive voice - "is the voluntary expression of ideas, information or opinions focused on effecting organizationally functional change to the work context". Constructive voice is similar to the pro-social voice of Van Dyne et al. (2003), the OCB voice of Van Dyne and LePine (1998) and the promotive and prohibitive voice of Liang et al. (2012).

- Defensive voice - "is the voluntary expression of opposition to changing an organization's policies, procedures, programs, practices, etc., even when the proposed changes have merit or making changes is necessary". This type of voice is similar to the defensive type of voice posited by Van Dyne et al. (2003).

- Destructive voice - "is the voluntary expression of hurtful, critical, or debasing opinions regarding work policies, practices, procedures, etc". This type of voice is related to the active/destructive voice of Gorden (1988).

\subsection{Discussion}

This section discussed three main streams of research related to various typologies of voice. The works of Van Dyne et al. (2003), followed by Liang et al. (2012), and Maynes and Podsakoff (2014) were emphasised. For this research, the comprehensive typology by Maynes and Podsakoff (2014) is selected. Presented along two intersecting dimensions preservation vs. challenge and promotive vs. prohibitive focus - the authors differentiate between four distinct types of voice: supportive, constructive, defensive and destructive, which are proposed as a guiding framework for distinguishing between different types of voice.

\section{Measurement of Voice}

Since the publication of their seminal work, Van Dyne and LePine's (1998) measuring instrument of voice became the obvious choice in many empirical studies and has remained so, even in recent years (e.g. (Gyensare, Arthur, Twumasi, \& Agyapong, 2019; Ng, Feldman, $\&$ Butts, 2014; Rees et al., 2013)). Although it demonstrates good psychometric properties (Morrison, 2011), at the time of development its authors already asserted the need for refinement of their measure: "another task for future research is refinement of the ...voice scales" (Van Dyne \& LePine, 1998, p. 118).

This chapter will discuss three measurement scales developed in response to Van Dyne and LePine's call for refinement. The instrument by Van Dyne et al. (2003) will be presented, followed by the measurement scale of Liang et al. (2012), and finally, the instrument of Maynes and Podsakoff (2014). In order to enhance understanding of the constructs and their operationalisation and adoption, sample items for each measuring scale presented will be provided.

Van Dyne, Ang and Botero (2003, pp. 1385, 1386) conceptualised silence and voice as multidimensional aggregate constructs (pro-social, acquiescent and defensive), with five sub-dimensions in each. In the recent empirical study by Kok, Sarikaya and Coban (2016, p. 24) the authors reported the reliability level of the 15-item scale for pro-social, acquiescent 
and defensive voice at a Cronbach's alpha of .733 - a level acceptable to consider the scale as reliable and appropriate for analysis. Similarly, acceptable reliability coefficients were reported by Li, Huang, Shu and Liu (2018) with a Cronbach's alpha for acquiescent voice .89, defensive voice .91 and pro-social voice .82. The sample items for each of the sub-dimensions (Van Dyne et al., 2003, p. 1386) are presented below:

- Pro-social voice: "This employee expresses solutions to problems with the cooperative motive of benefiting the organisation".

- Acquiescent voice: "This employee passively supports the ideas of others because he/she is disengaged".

- Defensive voice: "This employee does not express much except agreement with the group based on fear".

Interestingly, in their attempt to investigate what type of voice is significantly prevalent in organisations and whether voice behaviour differs in terms of demographical variables (gender, age, marital status, rank, education level, title and department), Kok et al. (2016) found that there is no significant difference between voice and any of demographical attributes. They also came to the conclusion that acquiescent voice (meaning that employees generally conform to other's opinions because of disbelief that their opinions would make any difference) is prevalent in the organisations sampled.

Liang et al. (2012) developed an instrument with two subscales to measure both promotive and prohibitive forms of voice. The authors selected items from a number of previously developed instruments (e.g. by Van Dyne et al. (2003) and Van Dyne and LePine (1998)) and tested them for reliability and validity. Liang et al. (2012) provided supportive evidence of the conceptual distinction between two types of voice and also demonstrated convergent and discriminant validity of promotive and prohibitive voice subscales. The supervisor ratings of employees' promotive and prohibitive voice are assessed on a 5-point Likert scale, where 1 is "Strongly disagree" and 5 is "Strongly agree". Each subscale consists of five items. Liang et al. (2012) report an alpha coefficient value of .87 for promotive voice and .86 for prohibitive voice. Sample items of both subscales are presented below (Liang et al., 2012, p. 79):

- Promotive voice: "This employee proactively develops and makes suggestions for issues that may influence the unit".

- Prohibitive voice: "This employee speaks up honestly with problems that might cause serious loss to the work unit, even when/though dissenting opinions exist".

Tested in recent studies, both subscales show good psychometric properties with a Cronbach's alpha of .75 (Jada \& Mukhopadhyay, 2018).

Although Liang et al.'s (2012) instrument is well supported by the research community, the alternative framework for operationalisation of voice by Meynes and Podsakoff (2014) is gaining its popularity for voice constructs due to its being more "crisp and refined" (Chamberlin et al., 2017, p. 42). 
Maynes and Podsakoff (2014) developed the organising framework which consists of supportive, constructive, defensive and destructive voice behaviours and validated the measurement scales of each sub-construct. Trimmed from an initial 48 voice scale items, the authors selected a final five items for each sub-construct based on: a) the content validity ratings, b) the ratings on the overall dimensions for voice (e.g. preservation/challenge or prohibitive/promotive), and c) analysis of whether the items reflect the collective domain of the construct (Maynes \& Podsakoff, 2014, p. 95).

Four types of voice are measured on a 7-point Likert scale, where 1 is "Strongly disagree" and 7 - "Strongly agree". The authors report the following reliabilities for each measure: a) The Cronbach's alpha for supportive voice is .89; b) The Cronbach's alpha for constructive voice is .95; c) The Cronbach's alpha for defensive voice is .92, and d) The Cronbach's alpha for destructive voice is .93. The sample items for each sub-dimension (Maynes \& Podsakoff, 2014, p. 96) are presented below:

- Supportive voice: "This employee defends useful organisational policies when other employees unfairly criticise the policies".

- Constructive voice: "This employee frequently makes suggestions about how to do things in new or more effective ways at work".

- Defensive voice: "This employee vocally argues against changing work practices, even when making the changes is necessary".

- Destructive voice: "This employee frequently makes overly critical comments regarding how things are done in the organisation".

Furthermore, the authors report the number of strengths of their voice measures. Firstly, the items possess adequate discriminant validity. Secondly, the measures exhibit an acceptable level of nomological and criterion-related validity. Lastly, the measures possess a high degree of veridical validity. On balance, the evidence shows that the instrument supports the validity of voice scales (Maynes \& Podsakoff, 2014, p. 105).

The question of whether the scales should be self-rated or other-rated sparked numerous debates. By way of example, Maynes and Podsakoff (2014) suggest that voice must be studied from the perspective of observers of voice events, rather than from the perspective of those speaking up. Unlike in the case of self-reports, which may be contaminated with bias (Nederof, 1985), the observers will be able to report on incidences of voice more objectively as they are visible to others. Maynes and Podsakoff's approach is aligned with the significant number of papers studying voice from the perspective of the observer (Burris, Detert, \& Chiaburu, 2008; LePine \& Van Dyne, 1998; Liang et al., 2012; Van Dyne \& LePine, 1998; Venkataramani \& Tangirala, 2010).

On that note, in their meta-analysis, $\mathrm{Ng}$ and Feldman (2012) report that 71 per cent of selected studies used self-report measures of voice. Across these results, the average reliability was .77 . The other 29 per cent of studies used other types of ratings in order to minimise common method bias. These ratings were by supervisors or peers, or were based on 
counts of suggestions made. Across those studies, the average reliability was .88. Although the number of studies that utilised other-rated questionnaires is smaller, the results demonstrate higher reliability than that achieved in the self-rated measures. This is in line with the recommendation by Van Dyne and LePine (1998) for assessing voice constructs from multiple perspectives, resulting in minimised common source and common method biases.

\subsection{Discussion}

In this section, various instruments for measuring voice construct were presented. Scholars can consider the merits of each framework and choose one over the other based on their utility and adoption. However, the measuring scale of voice by Meynes and Podsakoff (2014) seems to offer a broader spectrum of dimensions to assess four distinct types of voice supportive, constructive, defensive and destructive. Based on its high reliability and validity properties, the measure by Maynes and Podsakoff (2014) is recommended to researchers for quantitative studies of voice in the workplace.

\section{Conclusion}

The literature presents a wide range of works on employee voice, which is a significant factor in promoting innovative and novel ideas for organisational improvements (Gorden, 1988; Liang et al., 2012; Morrison, 2011; Van Dyne \& LePine, 1998). However, researchers often depict the concept in divergent ways, posing a challenge for scholars and practitioners as no standard definition or measuring instrument is available.

As a result of the analysis of how the voice concept was defined, organised and operationalised over the period of few decades - while also being based on a large spectrum of definitions, categorisations and the assessment of voice offered by a plethora of authors this paper focused on three researchers per section. The first section presented the most-accepted definitions of voice by Morrison (2011), Liang et al. (2012) and Meynes and Podsakoff (2014). The second section emphasised the works of Van Dyne et al. (2003), followed by Liang et al. (2012), and then by Maynes and Podsakoff (2014). The typologies of the last mentioned were used most often and tested in various conceptual models. Similarly, the final section discussed three instruments for measuring employee voice with relevant sub-scales developed by Van Dyne et al. (2003), Liang et al. (2012), and Maynes and Podsakoff (2014). It is clear that Liang et al. (2012) and Maynes and Podsakoff (2014) are the dominant figures across the three aspects.

Across sections, it appeared that the work of Liang and colleagues (2012) on promotive and prohibitive voice with their related measuring scales is most cited and most widely adopted by researchers after 2012. It also became clear that integrated and expanded work on voice by Maynes and Podsakoff (2014), which seems to drive the conceptualisation and measurement of voice presently, has been gaining support from many researchers and practitioners in recent years. Meynes and Podsakoff's (2014) categorisation of voice as four distinct types, being supportive, constructive, defensive and destructive, is suggested as a guiding framework resolving alternative views of voice and its dimensionality. As regards assessment, 
the instruments of Meynes and Podsakoff (2014), who developed and validated survey measures for each of four types of voice, demonstrated solid psychometric properties.

To achieve coherence in research, it would be wise to stick to one theory when dealing with all aspects of the research. Within this context, that of Meynes and Podsakoff (2014) seems to be authoritative on all aspects. This analysis suggests that the definition, the typology and the measurement of voice, as culminating in the work of Maynes and Podsakoff (2014), should be adopted. Following these authors' guidelines, it is suggested that voice should be defined as an "individual's voluntary and open communication directed toward individuals within the organization that is focused on influencing the context of work environment (p. 88), that four types of voice (supportive, constructive, defensive and destructive) are present, and finally, that the assessment instrument of voice developed by Meynes and Podsakoff (2014) is best suited to aligning new research efforts with those of the past.

The current review succeeds in integrating the extant knowledge on the topic and presenting it in an operationalised manner. Academics and practitioners alike are now equipped with most adopted definitions, typologies and measuring instruments related to different types of employee voice behaviour. This will allow them to engage in discussions on the topic with greater confidence, will facilitate research in the future and, importantly, will allow them to align the findings of their research with the existing body of knowledge.

\section{Reference}

Agarwal, U. A. (2014). Linking justice, trust and innovative work behaviour to work engagement. Personnel Review, 43(1), 41-73. https://doi.org/10.1108/pr-02-2012-0019

Barry, M., \& Wilkinson, A. (2016). Pro-Social or Pro-Management? A critique of the conception of employee voice as a pro-social behaviour within organizational behaviour. British Journal of Industrial Relations, 54(2), 261-284. https://doi.org/10.1111/bjir.12114

Bashshur, M. R., \& Oc, B. (2015). When voice matters: A multilevel review of the impact of voice in organizations. Journal of Management, 41(5), 1530-1554. https://doi.org/10.1177/0149206314558302

Bos-Nehles, A., Renkema, M., \& Janssen, M. (2017). HRM and innovative work behaviour: A systematic literature review. Personnel Review, 46(7), 1228-1253. https://doi.org/10.1108/PR-09-2016-0257

Budd, J. W. (2004). Employment with a human face: Balancing efficiency, equity, and voice. Cornell University Press.

Burris, E. R., Detert, J. R., \& Chiaburu, D. S. (2008). Quitting before leaving: The mediating effects of psychological attachment and detachment on voice. Journal of Applied Psychology, 93(4), 912-922. https://doi.org/10.1037/0021-9010.93.4.912

Chamberlin, M., Newton, D. W., \& LePine, J. A. (2017). A Meta-analysis of voice and its promotive and prohibitive forms: identification of key associations, distinctions, and future research directions. Personnel Psychology, 70(1), 11-71. https://doi.org/10.1111/peps.12185 


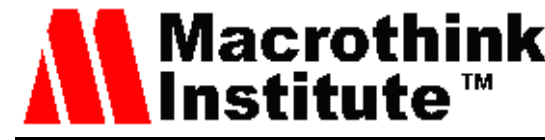

International Journal of Human Resource Studies

ISSN 2162-3058

2020, Vol. 10, No. 3

Detert, J. R., \& Burris, E. R. (2007). Leadership behavior and employee voice: Is the door really open? Academy of Management Journal, 50(4), 869-884. https://doi.org/10.5465/AMJ.2007.26279183

Freeman, R. B., \& Medoff, J. L. (1984). Trade unions and productivity: Some new evidence on an old issue. The ANNALS of the American Academy of Political and Social Science, 473(1), 149-164.

Gorden, W. I. (1988). Range of employee voice. Employee Responsibilities and Rights Journal, 1, 283-299.

Gyensare, M., Arthur, R., Twumasi, E., \& Agyapong, J. A. (2019). Leader effectiveness-the missing link in the relationship between employee voice and engagement. Cogent Business and Management, 6(1). https://doi.org/10.1080/23311975.2019.1634910

Hirschman, A. O. (1970). Exit, voice, and loyalty: Responses to decline in firms, organizations, and states. Harvard Iniversity Press.

Jada, U. R., \& Mukhopadhyay, S. (2018). Empowering leadership and constructive voice behavior: a moderated mediated model. International Journal of Organizational Analysis, 26(2), 226-241. https://doi.org/10.1108/IJOA-03-2017-1146

Kok, S. B., Sarikaya, M., \& Coban, H. (2016). Organizational voice behaviour and its investigation in terms of organizational variables. European Scientific Journal, 12(35), 16-33. https://doi.org/10.19044/esj.2016.v12n35p16

LePine, J. A., \& Van Dyne, L. (1998). Predicting voice vehavior in work groups. Journal of Applied Psychology, 83(6), 853-868. https://doi.org/10.1037/0021-9010.83.6.853

Li, H. U., Huang, S., Shu, J., \& Liu, C. (2018). Employee work performance mediates empowering leader behavior and employee voice. Social Behavior and Personality, 46(12), 1997-2008. https://doi.org/10.2224/sbp.7124

Liang, J., Farh, C., \& Farh, J.-L. (2012). Psychological antecedents of promotive and prohibitive voice: A two-wave examination. The Academy of Management Journal, 55(1), 71-92.

Maynes, T. D., \& Podsakoff, P. M. (2014). Speaking more broadly: An examination of the nature, antecedents, and consequences of an expanded set of employee voice behaviors. Journal of Applied Psychology, 99(1), 87-112. https://doi.org/10.1037/a0034284

Morrison, E. (2011). Employee voice behavior: Integration and directions for future research. Academy of Management Annals, 5(1), 373-412. https://doi.org/10.1080/19416520.2011.574506

Morrison, E., \& Milliken, F. J. (2000). Organizational silence: A barrier to change and development in a pluralistic world. Academy of Management Review, 25(4), 706-725.

Mowbray, P. K., Wilkinson, A., \& Tse, H. H. M. (2015). An integrative review of employee voice: Identifying a common conceptualization and research agenda. International Journal of 
Management Reviews, 17(3), 382-400. https://doi.org/10.1111/ijmr.12045

Nederof, A. J. (1985). Methods of coping with social desirability bias: A review. Journal of Social Psychology, 15, 263-280.

Ng, T. W. H., \& Feldman, D. C. (2012). Employee voice behavior: A meta-analytic test of the conservation of resources framework. Journal of Organizational Behavior, 33(2), 216-234. https://doi.org/10.1002/job

Ng, T. W. H., Feldman, D. C., \& Butts, M. M. (2014). Psychological contract breaches and employee voice behaviour: The moderating effects of changes in social relationships. European Journal of Work and Organizational Psychology, 23(4), 537-553. https://doi.org/10.1080/1359432X.2013.766394

Rees, C., Alfes, K., \& Gatenby, M. (2013). Employee voice and engagement: Connections and consequences. International Journal of Human Resource Management, 24(14), 2780-2798. https://doi.org/10.1080/09585192.2013.763843

Robinson, S. L. (1996). Trust and breach of the psychological contract. Administrative Science Quarterly, 41(4), 574-599.

Robinson, S. L., \& Morrison, E. W. (1995). Psychological contracts and OCB: The effect of unfulfilled obligations on civic virtue behavior. Journal of Organizational Behavior, 16(3), 289-298. https://doi.org/10.1002/job.4030160309

Sanz-Valle, R., \& Jiménez-Jiménez, D. (2018). HRM and product innovation: Does innovative work behaviour mediate that relationship? Management Decision, MD-04-2017-0404. https://doi.org/10.1108/MD-04-2017-0404

Van Dyne, L., Ang, S., \& Botero, I. C. (2003). Conceptualizing employee silence and employee voice as multidimensional constructs. Journal of Management Studies, 40(6), 1359-1392. https://doi.org/10.1111/1467-6486.00384

Van Dyne, L., Cummings, L. L., \& Parks, J. M. (1995). Extra-role behaviors: In pursuit of construct and definitional clarity. Research in Organizational Behavior, 17, 215-285.

Van Dyne, L., \& LePine, J. A. (1998). Helping and voice extra-role behaviors: Evidence of construct and predictive validity. Academy of Management Journal, 41(1), 108-119. https://doi.org/10.2307/256902

Veenendaal, A. A. R. (2015). Enhancing innovation at work through human resource management (University of Twente, Netherlands). Retrieved from http://doc.utwente.nl/95750/1/thesis_A_Veenendaal.pdf

Venkataramani, V., \& Tangirala, S. (2010). When and why do central employees speak up? An examination of mediating and moderating variables. Journal of Applied Psychology, 95(3), 582-591. https://doi.org/10.1037/a0018315

Wang, Y., Zheng, Y., \& Zhu, Y. (2018). How transformational leadership influences employee voice behavior: The roles of psychological capital and organizational identification. Social 
Behavior and Personality, 46(2), 313-321. https://doi.org/10.2224/sbp.6619

\section{Copyright Disclaimer}

Copyright for this article is retained by the author(s), with first publication rights granted to the journal.

This is an open-access article distributed under the terms and conditions of the Creative Commons Attribution license (http://creativecommons.org/licenses/by/4.0/). 